\title{
Comparing the effects of different cell death programs in tumor progression and immunotherapy
}

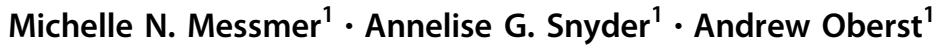

Received: 31 May 2018 / Revised: 21 September 2018 / Accepted: 26 September 2018 / Published online: 19 October 2018

(c) ADMC Associazione Differenziamento e Morte Cellulare 2018

\begin{abstract}
Our conception of programmed cell death has expanded beyond apoptosis to encompass additional forms of cell suicide, including necroptosis and pyroptosis; these cell death modalities are notable for their diverse and emerging roles in engaging the immune system. Concurrently, treatments that activate the immune system to combat cancer have achieved remarkable success in the clinic. These two scientific narratives converge to provide new perspectives on the role of programmed cell death in cancer therapy. This review focuses on our current understanding of the relationship between apoptosis and antitumor immune responses and the emerging evidence that induction of alternate death pathways such as necroptosis could improve therapeutic outcomes.
\end{abstract}

\section{Facts}

- Several signaling pathways have been defined for specific forms of cell death, including apoptosis and necroptosis.

- Apoptosis is engaged during development and tissue homeostasis, while necroptosis normally is not.

- Apoptosis has been implicated in immune suppression and promoting tumor growth.

- Necroptosis is engaged during infection and following specific cell stress signals.

- Necroptosis is associated with inflammatory cytokine production and priming of adaptive immune responses.
These authors contributed equally: Michelle N. Messmer, Annelise G. Snyder

Edited by F. Pentimalli

Andrew Oberst

Oberst@uw.edu

1 Department of Immunology, University of Washington, Seattle, WA 98109, USA

\section{Open questions}

- How does necroptosis engage inflammation and adaptive immunity, and how does this differ from apoptosis or unprogrammed necrosis?

- Can therapies be found that preferentially trigger immunogenic programmed cell death, such as necroptosis, in tumor cells?

- What therapies maximize the immunogenicity of apoptosis, a classically nonimmunogenic form of cell death?

- Can inflammatory forms of tumor cell death be used as a novel type of prophylactic tumor vaccination for tumors with conserved antigens?

- Will maximizing the immunogenicity of tumor cell death synergize with emerging immunotherapies, such as immune checkpoint blockade?

\section{Introduction}

Programmed cell death (PCD) is required for normal growth and development, and maintenance of tissue homeostasis; in these contexts, cell death generally occurs via classical apoptosis. Additionally, evolution has selected for alternate forms of PCD not engaged during development but instead occur in response to pathogen exposure or during cellular stress. Such PCD include necroptosis, pyroptosis, ferroptosis and others, though importantly apoptosis can also be 


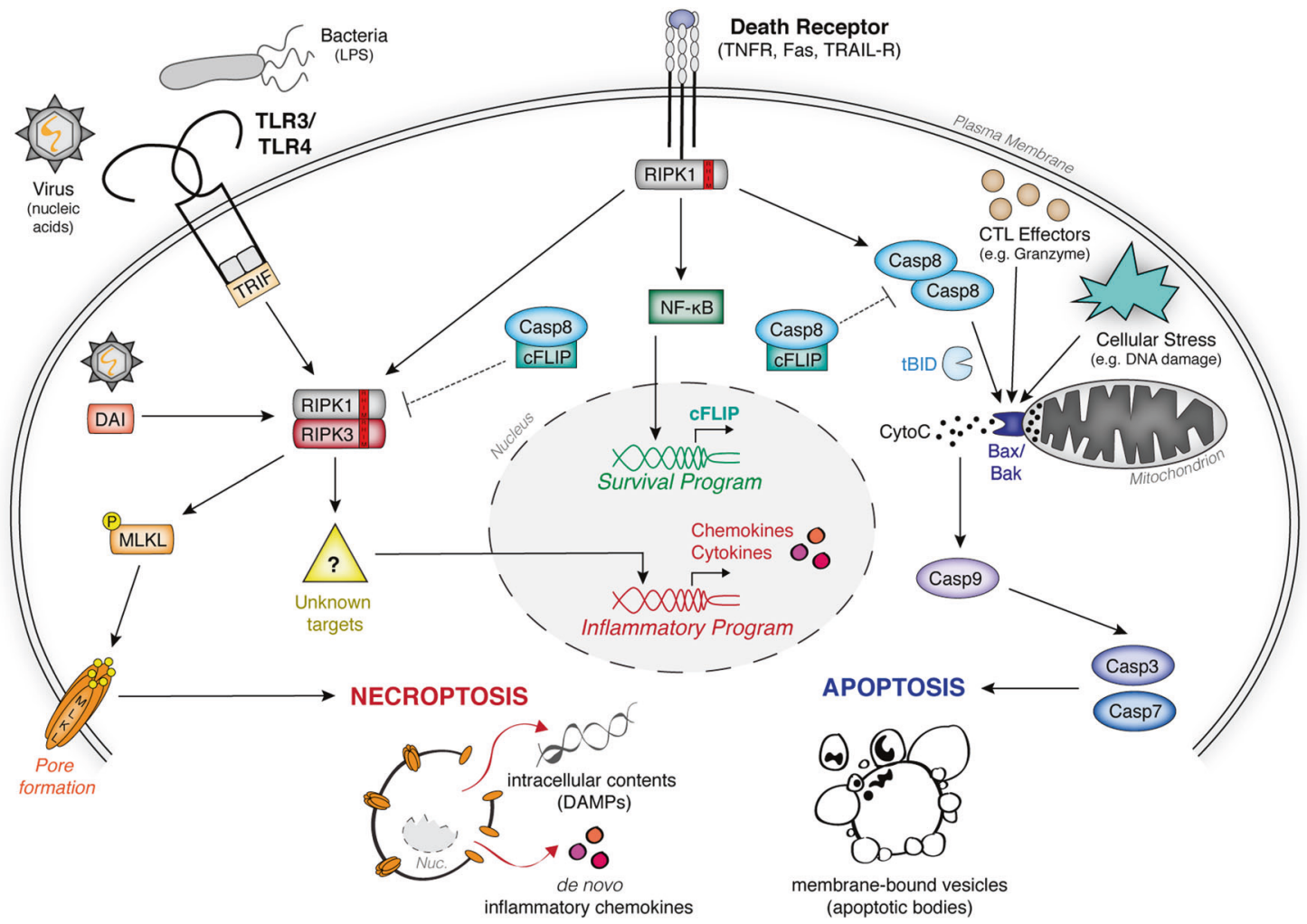

Fig. 1 Signaling pathways governing apoptosis and necroptosis. Binding of death receptor family members by their cognate ligands leads to pleiotropic signaling that can promote either survival, extrinsic apoptosis, or necroptosis, depending on the inhibition of proapoptotic caspase-8 homodimer complex and/or pronecroptotic RIPK1-RIPK3 hetero-oligomer. Upon inhibition of prosurvival NF- $\mathrm{KB}$ signaling, the apoptotic caspase- 8 complex dominates signaling, leading to downstream activation of executioner caspases -3 and -7 and subsequent induction of apoptosis. Intrinsic apoptosis occurs following mitochondrial perturbation leading to cytochrome $c$ release and subsequent caspase-9 apoptosome complex formation, which converges upon the activation of executioner caspases -3 and -7 . Cytotoxic $\mathrm{T}$ lymphocytes

triggered by similar stimuli. Distinct forms of PCD are defined by both specific signaling molecules activated downstream of death-inducing stimuli as well as characteristic morphologies of dying cells following initiation of these programs. This is in contrast to unprogrammed lytic necrosis, or cell death due to loss of plasma membrane integrity mediated by physical stress, which releases cellular contents into the extracellular space independent of any signaling cascades. Several reviews have extensively covered the signaling requirements for distinct PCD pathways [1-9].

Although molecular mediators of each PCD pathway have been identified, the field has only recently focused on how the immune system mechanistically differentiates between these death modalities. In particular, the effects of inflammatory or immunogenic PCD on the initiation of antitumor immune responses are just beginning to be defined. This review focuses primarily on apoptosis and necroptosis as (1) they
(CTL) also trigger intrinsic apoptosis by perforin-mediated delivery of granzyme B. In the presence of caspase inhibition, the RHIM-RHIM domain interactions allow for assembly of RIPK1-RIPK3 hetero-oligomers, and necrosome signaling dominates. This leads to (1) phosphorylation and activation of the pore-forming executioner MLKL, and (2) de novo inflammatory gene expression by necroptotic cells through poorly defined mechanisms. Aside from extrinsic death receptor signaling, the RIPK1-RIPK3 necrosome complex can also be activated through virus- or bacteria-induced TLR3/4 signaling in conjunction with the adaptor molecule TRIF, or upon activation of the intracellular sensor DAI during certain viral infections

represent two extremes on the PCD spectrum in terms of inflammation, (2) they often directly antagonize each other, and (3) there is a strong body of evidence for their roles in cancer from which to draw. Abbreviated discussion of the signaling pathways for these two forms of PCD are included below and summarized in Fig. 1.

\section{Apoptotic signaling}

Apoptosis is the major cell death pathway engaged during development and tissue homeostasis, but can also be induced downstream of certain cellular stresses such as infection. There are two pathways for apoptosis engagement-either extrinsic or intrinsic - that are summarized in Fig. 1 and extensively reviewed elsewhere $[1,2,10-15]$. Both result in activation of cysteine proteases, termed caspases, which trigger cell death with characteristic morphology involving nuclear condensation and membrane blebbing. 
Extrinsic apoptosis can be engaged downstream of death receptor (DR) signaling at the plasma membrane, including binding of TNF to TNFR1/2, FasL-Fas interactions, or TRAIL-TRAIL-R activation, though the exact signaling pathways they engage are distinctive. Extrinsic apoptosis requires recruitment of the adaptor protein Fas-associated death domain (FADD), which activates the apical signaling enzyme caspase- 8 through formation and autocatalytic stabilization of caspase- 8 homodimers. Cleaved caspase- 8 homodimers can then directly activate executioner caspases, caspase-3 and caspase-7, or activate mitochondrial apoptosis via cleavage of Bid. Executioner caspases-3 and-7 cleave aspartate residues in a wide variety of intracellular proteins, leading to catastrophic loss of cellular function and cellular dismantling [10]. DR signaling does not exclusively trigger apoptosis; indeed, NF- $\mathrm{KB}$ and mitogen-activated protein kinase (MAPK)-dependent transcription downstream of DR ligation can actively suppress DR-induced apoptotic signaling. The caspase paralog cFLIP is another notable target of DR-mediated transcriptional signaling [16]. In some contexts, it forms a suppressive heterodimer with caspase-8, preventing further proapoptotic signaling [17]. DR-induced apoptosis can also be blocked by inhibitor of apoptosis (IAP) E3 ligases or by Fas apoptosis inhibitory molecules (FAIMs). Taken together, a paradigm emerges that DR engagement triggers diverse inflammatory transcriptional programs; apoptosis occurs upon relief of cFLIP, IAP-, and/or FAIM-mediated inhibition.

Intrinsic apoptosis converges on the same executioner caspases, caspases -3 and -7 , but differs from extrinsic apoptosis with respect to upstream signaling [1, 2]. Intrinsic apoptosis can be initiated by a variety of cellular stressors such as growth factor withdrawal, replication stress, DNA damage, and ER stress. Such stressors modulate Bcl-2 proteins. The Bcl-2 family includes both pro- and antiapoptotic members, and the balance between these constituents determines cellular commitment to apoptosis. Proapoptotic Bcl-2 family members Bax, Bak and/or Bok mediate mitochondrial outer membrane permeabilization (MOMP), which releases cytochrome $c$ (cytoC) from the mitochondrial intermembrane space into the cytosol [18]. Release of cytoC induces oligomerization of Apaf- 1 in complex with the apical caspase of intrinsic apoptosis, caspase-9, to form a complex termed the "apoptosome" [13, 19]. Caspase- 9 then activates executioner caspases -3 and -7 , triggering cell destruction. Notably, this mitochondrial pathway can also be engaged by extrinsic apoptosis through caspase-8-mediated activating cleavage of proapoptotic Bcl2 family member Bid.

The morphology of extrinsic or intrinsic apoptotic death is essentially the same [11], as apoptotic cells undergo chromatin condensation and DNA cleavage accompanied by cellular shrinkage. The cell dissociates into membrane- bound vesicles termed apoptotic bodies, which neatly package intracellular contents and dying cell organelles away from the extracellular space. These apoptotic bodies, coated in "eat-me" signals such as phosphatidylserine (PS) and calreticulin (CRT), are rapidly cleared by phagocytes through a process known as efferocytosis [20, 21]. Notably, because apoptosis occurs under homeostatic conditions, efferocytosis is typically viewed as noninflammatory (Fig. 2a). Indeed, mutations in genes associated with the proper packaging, recognition, and breakdown of apoptotic cells in the absence of any other infection or damage signals are associated with a break in immunological tolerance and manifestation of autoimmune disorders including systemic lupus erythematosus [22-24].

\section{Necroptotic signaling}

In contrast to apoptosis, necroptosis is a more recently defined lytic form of PCD. While apoptosis depends on caspase activation, necroptosis requires activation of receptor-interacting protein kinases RIPK1 and RIPK3 (Fig. 1). Interestingly, RIPK1 is one of the adaptor proteins recruited to activate DR leading to NF- $\kappa B$-dependent gene expression [25]. As noted previously, NF- $\mathrm{kB}$ signaling leads to formation of inhibitory cFLIP/caspase- 8 heterodimers that prevent caspase-8 activation and subsequent extrinsic apoptosis. Notably, this heterodimer also suppresses necroptosis by inhibiting formation of RIPK1/RIPK3 heterodimers, which interact via RIP homotypic interaction motif (RHIM) domains present on both RIPK1 and RIPK3 $[5,26,27]$. Thus, necroptosis downstream of DR ligation requires inhibition of caspase- 8 through either viral effector proteins (such as the vICA protein encoded by MCMV) [28], pharmacological inhibitors (such as pan-caspase inhibitors zVAD-fmk or QVD-OPh), or possibly by loss of caspase- 8 (observed in neuroendocrine cancers and others) [29]. In addition to DR signaling, evidence suggests RIPK3 can be activated downstream of viral sensing by the receptor DAI [28, 30], viral nucleic acids detected by TLR3 [31, 32], or bacterial lipopolysaccharide sensed via TLR4 [33].

Once RIPK3 is activated it engages in pleiotropic signaling that appears to be highly cell type- and contextspecific (reviewed in ref. [34]). Classically, RIPK1-RIPK3 interaction through RHIM domains aggregates into a multiprotein signaling complex variously termed the "necrosome" or "ripoptosome". RIPK3 then phosphorylates the necroptosis executioner molecule mixed lineage kinase-like (MLKL) [35]. Phosphorylated MLKL forms homoheptameric pore-forming complexes which insert into cell membranes allowing cation entry and subsequent influx of extracellular fluid due to differences in osmolarity [36]. This influx is rapidly followed by catastrophic rupture of the plasma membrane and release of intracellular contents. 


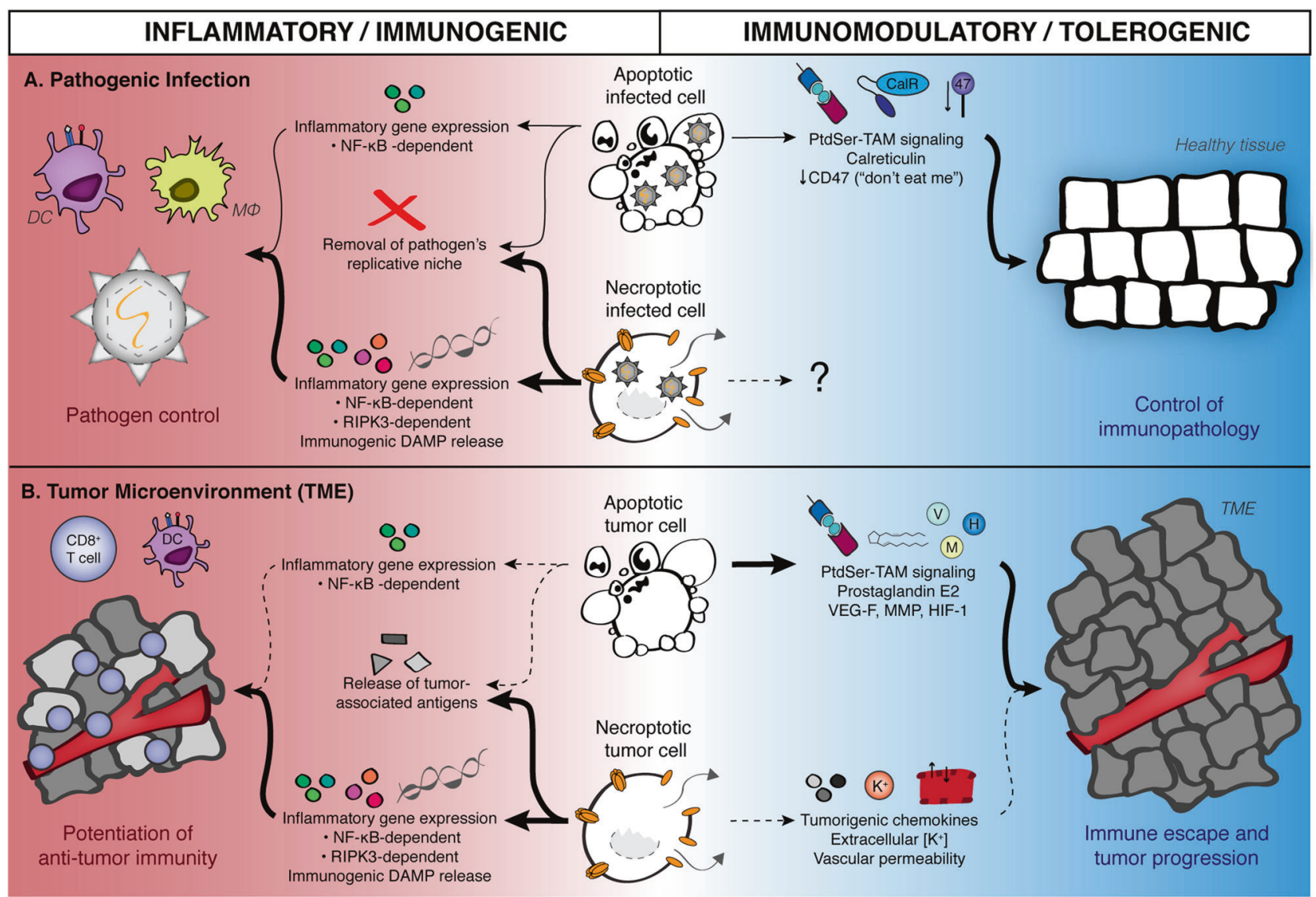

Fig. 2 Contribution of apoptosis and necroptosis to inflammation and immunogenicity during infection and tumorigenesis. a During pathogenic infection, stimulation of apoptosis or necroptosis in infected cells leads to the production of a variety of inflammatory mediators in conjunction with removal of the pathogen's intracellular replicative niche, enabling pathogen control and promoting clearance. Additional inflammatory signals derived from RIPK3 activation and release of damage-associated molecular patterns (DAMPs) due to necroptotic cell lysis lead us to believe that necroptosis is a more potently immunogenic form of PCD during pathogen infection. Signals derived from apoptotic cells can also promote the resolution of inflammation, allowing for infected tissues to return to homeostatic conditions. Note that no known role has been defined for necroptosis in promoting the control of tissue

Thus, necroptosis is a lytic cell death program in sharp contrast to apoptosis; there is limited compartmentalization of organelles, and no ordered packaging of cell-associated debris for clearance by professional phagocytes. Necroptotic lysis releases several known immunogenic molecules, termed damage-associated molecular patterns (DAMPs), which can stimulate innate immune pattern recognition receptors (PRRs). Such DAMPs include self-nucleic acids that interact with PRRs typically associated with detecting viral DNA such as cGAS/STING [37], polymerized actin that can be recognized by Clec9a/DNGR1 [38, 39], HMGB1 that activates RAGE [40, 41], ATP that activates P2X7 [42, 43], and CRT that activates CD91 $[44,45]$. immunopathology in the context of infection. b Apoptosis and necroptosis may promote analogous responses in the tumor microenvironment, although this has been examined less extensively within the cell death signaling field. Both apoptotic and necroptotic tumor cells can serve as a source of tumor-associated antigens, as well as induce NF- $\mathrm{kB}$ signaling. As with pathogenic infection, necroptotic cells can also serve as a source of RIPK3-dependent inflammatory genes (such as chemokines and cytokines), as well as cell-associated immunostimulatory DAMPs; all of these factors may contribute to necroptotic cells providing predominantly immunogenic signals within the tumor microenvironment. Conversely, there is evidence for protumorigenic roles of signals derived from both apoptotic as well as necroptotic (or necrotic) tumor cells

Originally, immune stimulation by necroptosis was primarily attributed to this release of DAMPs and subsequent activation of PRRs. However, the pattern of DAMPs released is virtually indistinguishable from other lytic forms of cell death including unprogrammed necrosis, or cell rupture following caspase-1-dependent pyroptosis [46]. Growing evidence indicates that necroptosis drives immune responses independent of - or in addition to-lytic MLKLmediated death through other ripoptosome signaling [33, 47-50]. Mice lacking caspase- 8 are embryonic lethal due to RIP kinase-induced necroptosis; additional loss of MLKL or RIPK3 results in viable offspring but subsequent development of autoimmune disorders, with earlier onset in MLKL-deficient mice implicating MLKL-independent 
effects of RIPK3 [47]. In a vaccination model, the ability of necroptotic cells to cross-prime antigen-specific cytotoxic $\mathrm{CD}^{+} \mathrm{T}$ cells (CTL) required RIPK1-mediated $\mathrm{NF}-\kappa \mathrm{B}$ activation for production of proinflammatory cytokines and chemokines [48]. In this system, necroptotic cells incapable of signaling via RIPK1 due to disrupted RHIM binding still died following RIPK3/MLKL activation, with lytic DAMP release, but failed to cross-prime. During West Nile virus infection in the brain, RIPK3 activation produced proinflammatory chemokines that mediated leukocyte recruitment which was required for viral control [49]. Notably, this therapeutic effect of RIPK3 activation occurs independently of necroptotic death, as infected neurons are resistant to RIPK3-dependent lytic cell death.

Although the mechanisms whereby RIPK1 and/or RIPK3 upregulate proinflammatory gene expression remain to be elucidated, it has become apparent that this regulation contributes to necroptotic cell immunogenicity independent of lytic cell death and DAMP release. Because necroptosis appears to have evolved as an antiviral form of cellular suicide, the current model is that necroptosis both eliminates a pathogen's replicative niche through deletion of infected cells while simultaneously providing a burst of de novo inflammatory signaling for recruitment and activation of leukocytes to the site of necroptotic cell death $[6,51]$ (Fig. 2a).

\section{Endogenous engagement of PCD in the tumor microenvironment during tumorigenesis and tumor progression}

Cancer represents a particular challenge when considering the impact of cellular death; various environmental pressures have been placed on cancer cells to suppress one or more death pathways as they undergo continuous rounds of proliferation driven by dysregulated signaling and extensive mutation. This section summarizes what is known about endogenous engagement or activation of PCD, and how these processes impact oncogenesis.

\section{Apoptosis is commonly engaged, and evaded, during oncogenesis}

As the first PCD pathway described, apoptosis is wellstudied in cancer; due to the commonality of this occurrence, avoiding apoptosis is considered one of cancer's defining hallmarks [52]. Cancer cells can downregulate or block apoptotic signaling through regulation of protein expression, protein-protein interactions, as well as metabolic regulation [53-55]. Major targets of this regulation include: loss or inhibition of transcription factor p53 that normally drives proapoptotic gene expression following cellular stress or damage [56], overexpression of antagonists to either extrinsic or intrinsic apoptotic pathways including increased expression of cFLIP and prosurvival BCL-2 protein family members [54, 55], and induction of the transcription factor hypoxia-inducible factor-1 (HIF-1) contributing to prosurvival metabolism, increased angiogenesis, and immune suppression [53, 57, 58]. This antiapoptotic regulation is not necessarily a direct cause of cancer but instead contributes to therapeutic resistance and disease progression in many cancer types.

The immune system also contributes selective pressure toward evasion of apoptosis. This process has been defined as "immunoediting" and encompasses the concepts of elimination (early immune clearance of abnormal cells), equilibrium (a balance of immune resistance and immune stimulation), and escape (eventual outgrowth of tumors due to successful immune evasion or immunosuppression) [54, 59]. Early during oncogenesis, abnormal cells expressing mutated or modified proteins can stimulate immune responses by CTL, while overexpression of stress-related surface proteins or downregulation of HLA can stimulate NK cells. CTL and NK cells use similar methods to induce cancer cell death; they release perforin and granzyme B into target cells to stimulate intrinsic apoptosis, or engage FasL-Fas to trigger extrinsic apoptosis. However, as described earlier, cancer cells have multiple mechanisms to subvert these apoptotic pathways and can thereby become resistant to immune attack [60, 61]. Additionally, inflammatory events following immune recognition and activation, particularly production of interferon gamma (IFN $\gamma$ ), contribute to increased expression of PD-L1 on cancer cells [62]. PD-L1 is the ligand for PD-1, a negative regulatory receptor expressed on T cells including CTL. Engagement of PD-1 leads to suppressed T-cell function and even T-cell apoptosis [62]. Thus, cancer clones may be selected that are resistant to immune-mediated apoptosis, while simultaneously inducing apoptotic death in responding lymphocytes.

Despite early pressures to lose proapoptotic signaling, new work highlights the contribution of apoptosis to cancer progression [12, 63, 64] (Fig. 2b). Tumors with high rates of spontaneous apoptotic death exhibit increased angiogenesis, increased risk of metastasis, and reduced patient survival, though these effects may be tumor type-specific [12, 63]. Apoptosis downstream of DNA-damaging agents has been implicated in lymphomagenesis due to the forced cycling of progenitor cells $[65,66]$. Engulfment of apoptotic debris by macrophages, as well as signaling by the caspase-3-dependent prostaglandin E2, increases macrophage production of vascular endothelial growth factor and matrix-metallo-proteinases responsible for extracellular matrix remodeling and implicated in metastatic progression [12]. Furthermore, apoptotic cell-derived prostaglandin E2 has also been implicated in promoting proliferation of surviving tumor cells following radiotherapy [63]. PS on the surface of apoptotic bodies allows binding of clotting 
factors to induce the coagulation cascade, which further contributes to a tumorigenic "wound healing" program in macrophages. Additional "find me" signals expressed during apoptosis such as CX3CL1 and lactoferrin have been associated with angiogenesis and promoting oncogenic receptor signaling $[63,64]$. Expression of "don't eat me" molecules such as surface protein CD47 on cancer cells can inhibit phagocytosis by signaling through $\operatorname{SIRP} \alpha$, a receptor of the immunoglobulin superfamily, on myeloid cells [64], reducing uptake of tumor-associated antigens for priming CTLs. While CD47 is overexpressed on many cancer cells, it is unclear how cancer cell death might regulate CD47 expression and function [64]. Thus, a complicated relationship exists between initial selective pressures to lose apoptotic sensitivity, followed by later protumor benefits provided by immune suppressive or modulatory effects of excessive apoptotic death.

\section{Nonprogrammed cell death in the tumor environment}

Apoptosis is not the only form of cell death commonly associated with tumors, as solid tumors often harbor regions of necrotic tissue. However, it is difficult to determine signaling events preceding apparent necrosis-necrotic regions may result from PCD, such as secondary necrosis following apoptotic death, or from non-PCD following physical loss of membrane integrity due to factors such as metabolic byproducts or high interstitial pressure. There are no good markers to distinguish between residual debris generated by nonprogrammed necrotic death and late-stage debris generated by PCD discussed in this review. The distinction largely relies on morphological assessment to rule out apoptosis through the lack of apoptotic bodies, chromatin condensation, blebbing, or cytoplasmic vacuolization [1].

Tumor necrosis aligns closely with areas of hypoxia, suggesting this is a primary driver of necrosis [67]. As noted earlier, hypoxia would normally trigger apoptosis, but in some cancer cells, disruption of apoptotic signaling prevents normal cell death progression, resulting in cytoC release without activation of caspases and eventual necrosis [68]. The extent of tumor necrosis typically associates with negative prognoses across a variety of tumor types, as necrosis correlates with tumor size and grade, lymph node metastasis, and angiogenesis, suggesting that the presence of necrotic tissue is detrimental to antitumor responses [67]. Some of these effects may be attributable to the overexpression of HIF-1 often detected surrounding these regions $[69,70]$.

\section{Roles for necroptosis during oncogenesis}

In contrast to apoptosis, there is less evidence supporting engagement of endogenous necroptotic signaling within tumor cells. Necroptosis is a more recently described form of PCD typically studied in the context of viral infection; as such, cancer biology researchers may not be aware of the vagaries of defining necroptosis within the tumor microenvironment. This is further complicated by the fact that necroptotic cells can be difficult to detect in vivo [71-73]. The only necroptosis-specific readouts are phosphorylation of RIPK3 and/or MLKL, both of which are transient events only detectable in a narrow time window between initial engagement of necroptotic signaling and breakdown of necroptotic cells. More thorough characterization of necroptotic signaling proteins within human or murine tumors will be needed to determine whether endogenous necroptosis is engaged across different tumor models.

Despite obstacles to detection, there is promising evidence that engagement of immunogenic RIPK3 signaling within tumor cells could benefit antitumor immunity. In a recent screen of over 60 murine cancer cell lines, the majority of nonhematopoietic lines lacked RIPK3 protein expression; mechanistically, this silencing was attributed to inhibitory methylation of the Ripk3 promoter [74]. Indeed, RIPK3 protein expression was similarly silenced in samples from human AML and breast cancer patients [74]. Additionally, RIPK3 mRNA is decreased in human colorectal cancer (CRC) tissues compared to healthy colon controls [75], and loss of RIPK3 is associated with tumor progression in CRC [76]. Conversely, increased expression of RIPK3 positively correlates with favorable outcomes in a variety of human tumors, including $\mathrm{HPV}^{+}$cervical cancer [77] and AML [78]. Consistent with the idea that RIPK3 expression promotes antitumor responses, the locus of the RIPK3 gene (chromosome 14q11.2) [79] is frequently mutated in several types of neoplasia, including nasopharyngeal carcinoma [80] and acute lymphoblastic leukemia [81], although it remains to be determined whether these mutations are specifically within the RIPK3 gene. Notably, complete loss of necroptotic components such as RIPK3 and MLKL does not result in spontaneous carcinogenesis [35, 82, 83], although combined loss of both necroptotic and apoptotic machinery results in lymphoproliferative disorders [26, 27, 47].

Collectively, these findings indicate that necroptotic signaling may exert a selective pressure during oncogenesis, whereby necroptosis-resistant clones are selected during immunoediting and subsequent immunoevasion. This offers a conceptually parallel selection mechanism as defined for the preferential outgrowth of apoptosis-resistant tumor cells [52, 55, 84]. Clones that lack signaling components required for multiple forms of PCD would have a considerable survival advantage over their apoptosis- or necroptosis-competent counterparts. In light of this, it is intriguing to consider therapeutic strategies for reconstituting tumor cells with PCD signaling components lost during 
selection to restore their ability to undergo immunogenic cell death programs. These findings also raise the question of which aspects of oncogenic transformation, tumor formation, and metastasis may engage necroptotic signaling to account for the apparent pressure against this pathway in tumor evolution.

Conversely, other groups have shown a protumorigenic role of RIPK3 signaling within tumors. In human pancreatic ductal adenocarcinoma (PDAC) samples, RIPK1, RIPK3, and $C X C L 1$ were highly expressed compared to healthy pancreatic tissue [85]. Interestingly, Ripk $3^{-/-}$mice were protected from PDAC tumor progression, which was associated with decreased CXCL1-dependent intratumoral infiltration of immunosuppressive myeloid-derived suppressor cells (MDSCs) and macrophages in conjunction with increased activation of tumor-infiltrating CTLs [86]. Furthermore, RIPK1 activation in murine B16.F10 primary melanoma tumors was associated with increased vascular permeability through p38/HSP27 activation, which enables tumor cell extravasation and dissemination throughout the vasculature, promoting metastasis [87].

Beyond direct evidence of protumorigenic RIPK1/ RIPK3 signaling, others have reported adverse prognoses associated with DAMPs released by lytic death. STING activation and type I IFN production promote oncogenesis in some settings [88], and even induction of immunological tolerance of tumor cells through downstream production of suppressive immune modulators including IDO, IL-10, and TGF- $\beta[89,90]$. Lastly, elevated extracellular potassium ion concentrations in areas of melanoma tumor necrosis suppress Akt-mTOR signaling and disable the function of intratumoral CTL [91], identifying an additional mechanism by which tumor necrosis promotes tumor survival by actively inhibiting CTL. Together, these papers identify a variety of mechanisms in which necroptotic signaling and its downstream byproducts may potentiate tumor subversion of the immune system.

Clearly, this second set of findings highlights the heterogeneous effects of RIPK1/RIPK3 signaling and its variability between immune, stromal, and tumor cell types, and how this affects the tumor microenvironment (Fig. 2b). It further stresses the paradoxical role of inflammation in the context of tumor immunity: although the established tumor microenvironment is typically viewed as immunosuppressive, proinflammatory signals are strongly implicated at various points during tumorigenesis and metastasis [92]. Therefore, it is likely that the specific combination of inflammatory signals derived from necroptotic cells, and the role they play in either promoting or suppressing antitumor immune responses, will prove to be context-specific [9397]. We stress an outstanding need for thorough characterization of downstream RIPK3 signaling effects across different cell types, and across diverse categories of neoplasia, in consideration of whether immunogenic PCD such as necroptosis could confer an overall therapeutic benefit to the patient.

\section{Therapies targeting specific PCD pathways in tumors and their effects on tumor immunity}

The primary goal of most cancer therapies is induction of tumor cell death to the point of tumor elimination and cure. With increasing awareness of therapy-induced immune responses, it is important to ask whether the specific form of induced PCD affects the longevity of tumor clearance following therapy-induced tumor debulking. This section will review methods of inducing specific forms of PCD and known immunogenic outcomes. These therapeutic approaches are also summarized in Table 1.

\section{Specific inducers of apoptosis}

Therapeutic agents have been developed to specifically trigger apoptosis by targeting the regulatory pathways that limit apoptotic death in cancer cells, primarily targeting BCL-2 proteins and IAPs. Structural mimetics of the BH3 domains of BCL-2 proteins have been developed to antagonize the antiapoptotic BCL-2 family members [98101]. While highly promising, their efficacy has been restricted by the inability to target them to specific cell types (i.e. cancer cells) without inducing apoptosis in healthy bystanders. Indeed, the ability of BH3-only proteins to induce death of immune cells has led to their proposed use as immune modulators during transplantation, graft versus host disease, and autoimmunity [101]. SMAC mimetics target cIAP family members and the endogenous inhibitor of caspases, XIAP [102]. SMAC mimetics bind to cIAPs and prevent their ability to inhibit caspases, but also stimulate cIAP auto-ubiquitination and degradation, thereby sensitizing cells to apoptotic death downstream of DR signaling [102]. Thus, combining SMAC mimetics with other death agonists improves the induction of cancer cell death. SMAC mimetics may also be capable of inducing necroptosis when coupled with caspase inhibition, potentially enhancing the immunogenicity of this therapy. However, as with $\mathrm{BH} 3$ mimetics, a lack of tumor cell specificity, and ancillary effects within the noncanonical NF-kB pathway, have limited their clinical success.

\section{Induction of immunogenic apoptosis}

Most standard-of-care anticancer therapies appear to induce apoptosis; however, a select few do so in an 


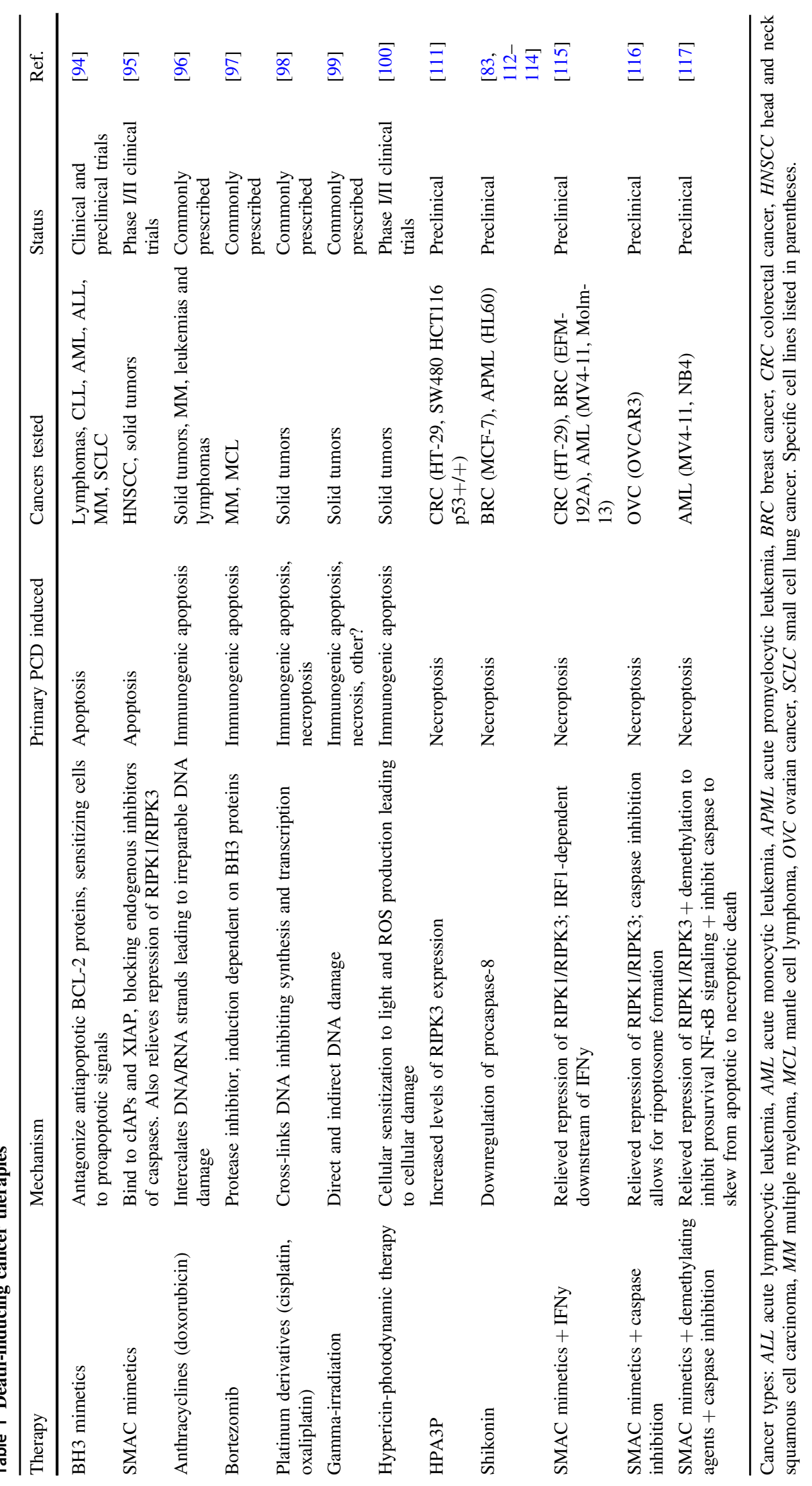


"immunogenic" way. This includes traditional chemotherapies such as anthracyclines [103], the protease inhibitor bortezomib [104], the platinum derivative oxaliplatin [105], as well as gamma-irradiation [106] and hypericin-photodynamic therapy [107]. While demonstrating caspase activation and apoptotic morphology, such therapies also trigger the release of DAMPs not normally associated with apoptosis such as CRT, HMGB1, ATP, type I IFN, nucleic acids, and annexin A1 [1]. Additionally, certain chemotherapies increase the expression of tumorassociated antigens, while upregulating expression of HLA and requisite processing machinery [108]. The exact signaling events determining immunogenic versus nonimmunogenic apoptosis are still under investigation, but potentially rely on elements of the ER stress response and intact exocytosis pathways [1].

Irradiation is of particular interest in triggering cancer death as it benefits from combination therapies with the immune checkpoint blocking antibody, anti-CTLA-4, contributing to abscopal tumor control [108, 109]. However, irradiation induces both apoptotic and necrotic death, and there may be an important distinction between the immunologic outcomes depending on which form of death dominates. Lowering the overall radiation dose as well as delivering this radiation in smaller fractions, rather than as a single dose, can increase the proportion of apoptotic death induced and better correlates with immune-mediated protection [108]. The exact signaling pathway whereby irradiation triggers apoptosis, necrosis, or other PCD is not clear based on clinical evidence; however, the form of death may also depend on the p53 status of tumor cells at the time of therapy. Abnormal p53 expression/function disrupts the ability of cells to respond appropriately to irradiationinduced DNA damage (by undergoing rapid apoptosis) and instead cells may proceed through the cell cycle unchecked, potentially resulting in delayed apoptosis, cellular senescence, or even activation of the necroptotic pathway [110].

Recent work has highlighted strategies to render apoptosis immunogenic by blocking aspects of its execution that silence the immune response to apoptotic cells. Genetic ablation of the executioner caspases was found to arrest rapid apoptosis, instead leading to engagement of STINGdependent IFN signaling due to release of mitochondrial DNA [111, 112]. Given this finding, subsequent efforts combined intrinsic apoptosis inducing BH3 mimetics with pharmacologic caspase inhibition. This combination induced MOMP but arrested apoptosis execution, instead engaging immunogenic STING signaling [113]. Importantly, this inhibition of executioner caspases does not rescue cell viability, as MOMP represents a cellular "point of no return". Rather, this strategy redirects apoptosis from a rapid immunosuppressive program to a slow, potentially immunogenic form of cell death. Clinical evidence is needed to show whether apoptosis-targeting therapies augment the immunogenicity of cell death in tumors, but the possible synergy between these strategies and immune checkpoint inhibitors is tantalizing.

\section{Specific targeting of necroptosis}

As discussed previously, extrinsic necroptosis requires DR engagement in the presence of caspase inhibition; accordingly, it is difficult to induce necroptosis in tumor cells without off-target toxicity associated with global caspase inhibition [114-116]. Furthermore, therapies targeting endogenous necroptotic signaling operate under the assumption that tumor cells have intact necroptotic signaling components. However, as discussed above, there is evidence for RIPK3 silencing or loss in many different tumor types. Nevertheless, pharmacologic compounds that stimulate necroptosis represent an alternative strategy for killing tumor cells resistant to apoptotic stimuli [117]. Examples of such compounds are highlighted in Table 1.

Several compounds have been shown to induce necroptosis in cancer cell lines in vitro. This includes the antimicrobial peptide HPA3P [118], the natural product Shikonin [90, 119-121], and several strategies using SMAC mimetics combined with IFN $\gamma$ [122], pan-caspase inhibitor zVAD [123], or demethylating agents and zVAD [124]. Cell culture models have also provided evidence of RIPK3 and/or MLKL activation following chemotherapy such as cisplatin [125, 126] or oxaliplatin [127].

The advantage of studying necroptosis in cell lines is the ability to confirm the specific activation of necroptotic signaling components; however, these studies do not account for off-target toxicity, or questions concerning pharmacokinetics and drug availability within the tumor microenvironment. A limited number of in vivo studies are beginning to show promising results using these therapies. In a model of multiple myeloma, the SMAC mimetic LCL161 triggered inflammatory cytokine secretion and activation of antitumor immune responses independent of direct tumor toxicity, which supported observations of durable antimyeloma responses in LCL161-treated patients [128]. Treatment of caspase-8deficient murine CRC tumors via intratumoral injection of LCL161 led to tumor regression; notably, these effects were seen both in hereditary murine ApcMin/+ tumors as well as a xenograft model of human HT-29 tumor cells [129]. Furthermore, tumor control by LCL161 required both caspase- 8 deficiency and RIPK3 expression in tumor cells, implying that these tumors were genetically sensitized to undergo necroptosis downstream of SMAC mimetic administration. Another group showed that Shikonin treatment of preclinical osteosarcoma cells induced RIPK1-dependent cell death in vitro, and that administration of Shikonin to intratibial osteosarcoma-bearing mice reduced both the size of the 
primary tumor as well as the number of lung metastases, prolonging animal survival [119]. As the mechanisms underlying Shikonin-induced necroptosis remain relatively poorly characterized, future investigation into the mechanism of action of Shikonin should include evaluation of caspase- 8 and cIAP expression within the targeted tumor cells.

Overall, these results highlight the need to screen patient tumors to confirm the presence of intact necroptotic signaling pathways and/or caspase deficiency prior to administration of pronecroptotic stimuli. Alternatively, exploring possible strategies to reinstate expression of necroptotic signaling components within tumor cells could represent another therapeutic target. Historically, work in the tumor gene therapy field has focused on using viral vectors to transduce tumor cells in situ to enforce expression of a wide variety of antitumor effectors, including inflammatory cytokines [130-132], Flt3L [133135], CD40L [136, 137], HLA re-expression [138], tumor suppressors [139], as well as suicide genes [140, 141]. Considering this evidence of success, one can envision future gene therapy strategies aimed at transducing tumor cells in situ to enforce expression of immunogenic cell death signaling components. Tumor cells could be rendered susceptible once again to apoptosis- or necroptosis-inducing stimuli to which they were previously refractory. Indeed, tumor cells reconstituted with activatable caspase-9 [142] or caspase-3 [143] via adenoviral gene delivery became sensitized to apoptosis in vivo, demonstrating that this approach could be successful in tumor immunotherapy.

\section{Outstanding questions/future perspectives}

While our understanding of immunogenic PCD has greatly expanded in recent years, important questions integrating this understanding with tumor immunotherapy remain.

\section{Could PCD "warm" tumors ahead of immunotherapy?}

Multiple studies have shown that the efficacy of immunotherapies such as immune checkpoint inhibition can be substantially improved upon coadministration with classic inducers of tumor cell death such as irradiation or cryotherapy [109, 144-146]. Considering the proinflammatory functions of RIPK1 or RIPK3 signaling, specifically inducing necroptosis may represent a more potently immunogenic form of cell death. This is particularly interesting in the context of immunologically "hot" versus "cold" tumors, which are defined by differential tumor infiltration of leukocytes, particularly CTLs [147, 148]. There are several mechanisms by which tumors exclude immune cell infiltration [149151]. Notably, patient responsiveness to tumor immunotherapy often requires a T-cell-inflamed phenotype [152-155]. Activation of either RIPK1 or RIPK3 leads to upregulation of inflammatory chemokines [48, 49], including CXCL9 and CXCL10, which drove chemotactic recruitment of $\mathrm{CXCR}^{+} \mathrm{CTL}$ into brains of WNV-infected mice [49]. If RIPK3 activation within tumors results in a similar induction of inflammatory chemokines and subsequent leukocyte infiltration, this could "warm" immunologically "cold" tumors, rendering them responsive to immunotherapies. Indeed, presence of intratumoral chemokines such as CCL2, CCL4, CXCL9, and CXCL10 positively correlates with CTL infiltration [156]. In evaluating the feasibility of incorporating necroptosis-inducing drugs into existing immunotherapy regimens, more studies in vivo are required to assess tumor cell specificity and overall efficacy of these therapies.

\section{How can knowledge of PCD signaling benefit tumor immunology?}

The tumor immunology field lacks a comprehensive understanding of how distinct PCD within tumors differentially modulates downstream immune responses. Considering advances in defining specific PCD signaling programs, in conjunction with recent efforts to stimulate innate immune pathways as targets of tumor immunotherapy, it would appear that the field is ready for more extensive interrogation of different forms of PCD. This is no trivial undertaking, as the complex signaling programs regulating PCD are likely to have considerable variation not only across healthy tissue and cell subsets, but also across different types of cancers, and exhibit further heterogeneity among patients due to genetic and environmental factors [157].

In summary, specific modulation of PCD within the tumor microenvironment represents a relatively poorly explored immunotherapeutic target. In considering the current immunotherapy landscape (Fig. 3), tumor cell death constitutes the most proximal event in the generation of an immune response against dying cell-derived antigens. Optimized combinations of PCD targeting and immunotherapy will likely act upon different stages of antitumor immune responses [144, 149]. One can envision future combination therapies whereby induction of (a) maximally immunogenic tumor cell death is coupled with (b) modulation of tumor-associated antigen-presenting cells in conjunction with (c) immune checkpoint blockade to maximize CTL killing of any remaining tumor cells. Of course, coadministration of multiple antitumor drugs will need to be carefully balanced with the need to suppress systemic inflammation and off-target attacks, as highlighted by recent issues with neurotoxicity and cytokine release syndrome observed in some patients [158-160]. Nevertheless, the 


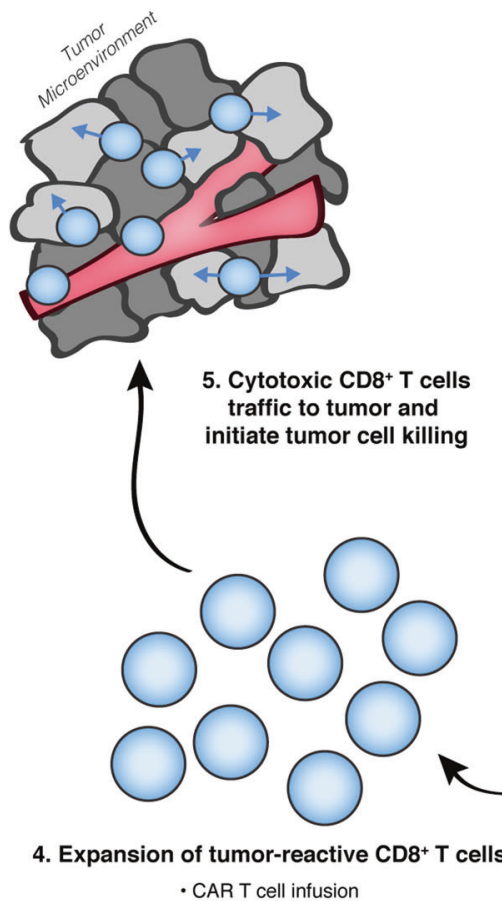

Fig. 3 Immunogenic cell death serves as proximal target within the current repertoire of tumor immunotherapy. Generation of cytotoxic $\mathrm{CD}^{+} \mathrm{T}$ cell (CTL)-mediated immunity against living tumor cell targets can be broadly separated into five steps: (1) Tumor cell death releases cell-associated antigens in the presence or absence of various immunogenic signals derived from dying cells; (2) tumor-associated antigen-presenting cells (tuAPCs) phagocytose, process, and crosspresent antigen from dying cells; (3) tumor-reactive CTLs recognize tumor antigen and become activated (priming in the tumor-draining lymph node) or reactivated (restimulation of existing CTLs) in the presence of functional tuAPCs; (4) activated CTL proliferate and

complex processes underlying tumor cell heterogeneity necessitate the expansion of treatments which can kill transformed cells that have escaped the selection pressures exerted by singular therapies to acquire immunotherapy resistance [161]. It is therefore an attractive hypothesis that targeting specific forms of immunogenic cell death may constitute a relatively unexplored orthogonal treatment modality in the future repertoire of tumor immunotherapies.

\section{Compliance with ethical standards}

Conflict of interest The authors declare that they have no conflict of interest.

\section{References}

1. Galluzzi L, Vitale I, Aaronson SA, Abrams JM, Adam D, Agostinis P, et al. Molecular mechanisms of cell death: recommendations of the Nomenclature Committee on Cell Death 2018. Cell Death Differ. 2018;25:486-541.
Antigen processing and activation of functional tumor APCs - Depletion of immunosuppressive myeloid cells - Stimulation of innate immune pathways
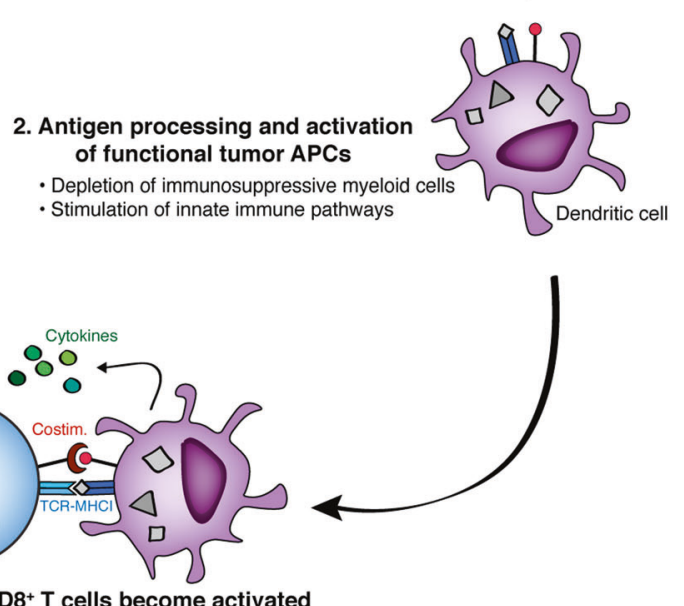

- Immune checkpoint blockade

expand; (5) activated and functionally capable CTLs traffic to the tumor microenvironment, where they recognize live tumor cell targets and exert their cytolytic effector function to promote tumor cell killing. Therapies with known mechanisms of action are listed below each step. Although different modalities of both programmed and unprogrammed cell death can be induced by a variety of chemotherapeutic agents, it remains to be determined which of these treatments maximizes the immunogenicity of dying cells within the tumor microenvironment. Strategy-driven selection of combination therapy regimens will likely necessitate inclusion of immunotherapy agents that best potentiate antitumor immunity at separate steps within this cycle

2. Elmore S. Apoptosis: a review of programmed cell death. Toxicol Pathol. 2007;35:495-516.

3. Yatim N, Cullen S, Albert ML. Dying cells actively regulate adaptive immune responses. Nat Rev Immunol. 2017;17: 262-75.

4. Grootjans S, Vanden Berghe T, Vandenabeele P. Initiation and execution mechanisms of necroptosis: an overview. Cell Death Differ. 2017;24:1184-95.

5. Weinlich R, Oberst A, Beere HM, Green DR. Necroptosis in development, inflammation and disease. Nat Rev Mol Cell Biol. 2017;18:127-36.

6. Orzalli MH, Kagan JC. Apoptosis and necroptosis as host defense strategies to prevent viral infection. Trends Cell Biol. 2017;27:800-9.

7. Vanden Berghe T, Hassannia B, Vandenabeele P. An outline of necrosome triggers. Cell Mol Life Sci. 2016;73:2137-52.

8. Wallach D, Kang TB, Dillon CP, Green DR. Programmed necrosis in inflammation: toward identification of the effector molecules. Science. 2016;352:aaf2154.

9. Czabotar PE, Lessene G, Strasser A, Adams JM. Control of apoptosis by the BCL-2 protein family: implications for physiology and therapy. Nat Rev Mol Cell Biol. 2014;15:49-63.

10. Dickens LS, Powley IR, Hughes MA, MacFarlane M. The 'complexities' of life and death: death receptor signalling platforms. Exp Cell Res. 2012;318:1269-77. 
11. Taylor RC, Cullen SP, Martin SJ. Apoptosis: controlled demolition at the cellular level. Nat Rev Mol Cell Biol. 2008;9:231-41.

12. Ucker DS, Levine JS. Exploitation of apoptotic regulation in cancer. Front Immunol. 2018;9:241.

13. Yuan S, Akey CW. Apoptosome structure, assembly, and procaspase activation. Structure. 2013;21:501-15.

14. Strasser A, Harris AW, Huang DC, Krammer PH, Cory S. Bcl-2 and Fas/APO-1 regulate distinct pathways to lymphocyte apoptosis. EMBO J. 1995;14:6136-47.

15. Jost PJ, Grabow S, Gray D, McKenzie MD, Nachbur U, Huang DC, et al. XIAP discriminates between type I and type II FASinduced apoptosis. Nature. 2009;460:1035-9.

16. Ozturk S, Schleich K, Lavrik IN. Cellular FLICE-like inhibitory proteins (c-FLIPs): fine-tuners of life and death decisions. Exp Cell Res. 2012;318:1324-31.

17. Hughes MA, Powley IR, Jukes-Jones R, Horn S, Feoktistova M, Fairall L, et al. Co-operative and hierarchical binding of c-FLIP and caspase-8: a unified model defines how c-FLIP isoforms differentially control cell fate. Mol Cell. 2016;61:834-49.

18. Lopez J, Tait SW. Mitochondrial apoptosis: killing cancer using the enemy within. Br J Cancer. 2015;112:957-62.

19. Shakeri R, Kheirollahi A, Davoodi J. Apaf-1: regulation and function in cell death. Biochimie. 2017;135:111-25.

20. Bosurgi L, Hughes LD, Rothlin CV, Ghosh S. Death begets a new beginning. Immunol Rev. 2017;280:8-25.

21. Kumar S, Calianese D, Birge RB. Efferocytosis of dying cells differentially modulate immunological outcomes in tumor microenvironment. Immunol Rev. 2017;280:149-64.

22. Elkon KB. Cell death, nucleic acids, and immunity: inflammation beyond the grave. Arthritis Rheumatol. 2018;70:805-16.

23. Nagata S, Hanayama R, Kawane K. Autoimmunity and the clearance of dead cells. Cell. 2010;140:619-30.

24. Baumann I, Kolowos W, Voll RE, Manger B, Gaipl U, Neuhuber WL, et al. Impaired uptake of apoptotic cells into tingible body macrophages in germinal centers of patients with systemic lupus erythematosus. Arthritis Rheum. 2002;46:191-201.

25. Ting AT, Bertrand MJM. More to life than NF-kappaB in TNFR1 signaling. Trends Immunol. 2016;37:535-45.

26. Oberst A, Dillon CP, Weinlich R, McCormick LL, Fitzgerald P, Pop C, et al. Catalytic activity of the caspase-8-FLIP(L) complex inhibits RIPK3-dependent necrosis. Nature. 2011;471:363-7.

27. Kaiser WJ, Upton JW, Long AB, Livingston-Rosanoff D, DaleyBauer LP, Hakem R, et al. RIP3 mediates the embryonic lethality of caspase-8-deficient mice. Nature. 2011;471:368-72.

28. Upton JW, Kaiser WJ, Mocarski ES. Virus inhibition of RIP3dependent necrosis. Cell Host Microbe. 2010;7:302-13.

29. Stupack DG. Caspase-8 as a therapeutic target in cancer. Cancer Lett. 2013;332:133-40.

30. Thapa RJ, Ingram JP, Ragan KB, Nogusa S, Boyd DF, Benitez $\mathrm{AA}$, et al. DAI Senses influenza A virus genomic RNA and activates RIPK3-dependent cell death. Cell Host Microbe. 2016;20:674-81.

31. Kaiser WJ, Sridharan H, Huang C, Mandal P, Upton JW, Gough PJ, et al. Toll-like receptor 3-mediated necrosis via TRIF, RIP3, and MLKL. J Biol Chem. 2013;288:31268-79.

32. He S, Liang Y, Shao F, Wang X. Toll-like receptors activate programmed necrosis in macrophages through a receptorinteracting kinase-3-mediated pathway. Proc Natl Acad Sci USA. 2011;108:20054-9.

33. Najjar M, Saleh D, Zelic M, Nogusa S, Shah S, Tai A, et al. RIPK1 and RIPK3 kinases promote cell-death-independent inflammation by Toll-like Receptor 4. Immunity. 2016;45:46-59.

34. Linkermann A, Green DR. Necroptosis. N Engl J Med. 2014;370:455-65.
35. Murphy JM, Czabotar PE, Hildebrand JM, Lucet IS, Zhang JG, Alvarez-Diaz $\mathrm{S}$, et al. The pseudokinase MLKL mediates necroptosis via a molecular switch mechanism. Immunity. 2013;39:443-53.

36. Zhang Y, Chen X, Gueydan C, Han J. Plasma membrane changes during programmed cell deaths. Cell Res. 2018;28:9-21.

37. Li T, Chen ZJ. The cGAS-cGAMP-STING pathway connects DNA damage to inflammation, senescence, and cancer. J Exp Med. 2018;215:1287-99.

38. Ahrens S, Zelenay S, Sancho D, Hanc P, Kjaer S, Feest C, et al. F-actin is an evolutionarily conserved damage-associated molecular pattern recognized by DNGR-1, a receptor for dead cells. Immunity. 2012;36:635-45.

39. Sancho D, Joffre OP, Keller AM, Rogers NC, Martinez D, Hernanz-Falcon $P$, et al. Identification of a dendritic cell receptor that couples sensing of necrosis to immunity. Nature. 2009;458:899-903.

40. Scaffidi P, Misteli T, Bianchi ME. Release of chromatin protein HMGB 1 by necrotic cells triggers inflammation. Nature. 2002;418:191-5.

41. Hreggvidsdottir HS, Lundberg AM, Aveberger AC, Klevenvall $\mathrm{L}$, Andersson U, Harris HE. High mobility group box protein 1 (HMGB1)-partner molecule complexes enhance cytokine production by signaling through the partner molecule receptor. Mol Med. 2012;18:224-30.

42. Lee BH, Hwang DM, Palaniyar N, Grinstein S, Philpott DJ, Hu J. Activation of $\mathrm{P} 2 \mathrm{X}(7)$ receptor by ATP plays an important role in regulating inflammatory responses during acute viral infection. PLoS ONE. 2012;7:e35812.

43. Riteau N, Baron L, Villeret B, Guillou N, Savigny F, Ryffel B, et al. ATP release and purinergic signaling: a common pathway for particle-mediated inflammasome activation. Cell Death Dis. 2012;3:e403.

44. Obeid M, Panaretakis T, Tesniere A, Joza N, Tufi R, Apetoh L, et al. Leveraging the immune system during chemotherapy: moving calreticulin to the cell surface converts apoptotic death from "silent" to immunogenic. Cancer Res. 2007;67:7941-4.

45. Gardai SJ, McPhillips KA, Frasch SC, Janssen WJ, Starefeldt A, Murphy-Ullrich JE, et al. Cell-surface calreticulin initiates clearance of viable or apoptotic cells through trans-activation of LRP on the phagocyte. Cell. 2005;123:321-34.

46. Shi J, Gao W, Shao F. Pyroptosis: gasdermin-mediated programmed necrotic cell death. Trends Biochem Sci. 2017;42:245-54.

47. Alvarez-Diaz S, Dillon CP, Lalaoui N, Tanzer MC, Rodriguez DA, Lin A, et al. The pseudokinase MLKL and the kinase RIPK3 have distinct roles in autoimmune disease caused by loss of death-receptor-induced apoptosis. Immunity. 2016;45:513-26.

48. Yatim N, Jusforgues-Saklani H, Orozco S, Schulz O, Barreira da Silva R. Reis e Sousa C, et al. RIPK1 and NF-kappaB signaling in dying cells determines cross-priming of CD8(+) $\mathrm{T}$ cells. Science. 2015;350:328-34.

49. Daniels BP, Snyder AG, Olsen TM, Orozco S, Oguin TH 3rd, Tait SWG, et al. RIPK3 restricts viral pathogenesis via cell death-independent neuroinflammation. Cell. 2017;169:301-13. e11.

50. Vince JE, Wong WW, Gentle I, Lawlor KE, Allam R, O'Reilly $\mathrm{L}$, et al. Inhibitor of apoptosis proteins limit RIP3 kinasedependent interleukin-1 activation. Immunity. 2012;36: 215-27.

51. Upton JW, Shubina M, Balachandran S. RIPK3-driven cell death during virus infections. Immunol Rev. 2017;277:90-101.

52. Hanahan D, Weinberg RA. Hallmarks of cancer: the next generation. Cell. 2011;144:646-74. 
53. Matsuura K, Canfield K, Feng W, Kurokawa M. Metabolic regulation of apoptosis in cancer. Int Rev Cell Mol Biol. 2016;327:43-87.

54. Yaacoub K, Pedeux R, Tarte K, Guillaudeux T. Role of the tumor microenvironment in regulating apoptosis and cancer progression. Cancer Lett. 2016;378:150-9.

55. Fernald K, Kurokawa M. Evading apoptosis in cancer. Trends Cell Biol. 2013;23:620-33.

56. Kaiser AM, Attardi LD. Deconstructing networks of p53mediated tumor suppression in vivo. Cell Death Differ. 2018;25: 93-103.

57. Liao D, Johnson RS. Hypoxia: a key regulator of angiogenesis in cancer. Cancer Metastas- Rev. 2007;26:281-90.

58. Bhattarai D, Xu X, Lee K. Hypoxia-inducible factor-1 (HIF-1) inhibitors from the last decade (2007 to 2016): a "structure -activity relationship" perspective. Med Res Rev. 2018;38: 1404-42.

59. Dunn GP, Old LJ, Schreiber RD. The three Es of cancer immunoediting. Annu Rev Immunol. 2004;22:329-60.

60. French LE, Tschopp J. Defective death receptor signaling as a cause of tumor immune escape. Semin Cancer Biol. 2002;12: $51-5$.

61. Otten HG, van Ginkel WG, Hagenbeek A, Petersen EJ. Prevalence and clinical significance of resistance to perforin- and FAS-mediated cell death in leukemia. Leukemia. 2004;18: 1401-5.

62. Kythreotou A, Siddique A, Mauri FA, Bower M, Pinato DJ. PDL1. J Clin Pathol. 2018;71:189-94.

63. Ichim G, Tait SW. A fate worse than death: apoptosis as an oncogenic process. Nat Rev Cancer. 2016;16:539-48.

64. Garg AD, Romano E, Rufo N, Agostinis P. Immunogenic versus tolerogenic phagocytosis during anticancer therapy: mechanisms and clinical translation. Cell Death Differ. 2016;23:938-51.

65. Labi V, Erlacher M, Krumschnabel G, Manzl C, Tzankov A, Pinon J, et al. Apoptosis of leukocytes triggered by acute DNA damage promotes lymphoma formation. Genes Dev. 2010;24: 1602-7.

66. Michalak EM, Vandenberg CJ, Delbridge AR, Wu L, Scott CL, Adams JM, et al. Apoptosis-promoted tumorigenesis: gammairradiation-induced thymic lymphomagenesis requires Pumadriven leukocyte death. Genes Dev. 2010;24:1608-13.

67. Richards CH, Mohammed Z, Qayyum T, Horgan PG, McMillan DC. The prognostic value of histological tumor necrosis in solid organ malignant disease: a systematic review. Future Oncol. 2011;7:1223-35.

68. Steinbach JP, Wolburg H, Klumpp A, Probst H, Weller M. Hypoxia-induced cell death in human malignant glioma cells: energy deprivation promotes decoupling of mitochondrial cytochrome $\mathrm{c}$ release from caspase processing and necrotic cell death. Cell Death Differ. 2003;10:823-32.

69. Vaupel P, Mayer A. Hypoxia in cancer: significance and impact on clinical outcome. Cancer Metastas- Rev. 2007;26: 225-39.

70. Kumar V, Gabrilovich DI. Hypoxia-inducible factors in regulation of immune responses in tumour microenvironment. Immunology. 2014;143:512-9.

71. Tonnus W, Linkermann A. The in vivo evidence for regulated necrosis. Immunol Rev. 2017;277:128-49.

72. He S, Huang S, Shen Z. Biomarkers for the detection of necroptosis. Cell Mol Life Sci. 2016;73:2177-81.

73. Jouan-Lanhouet S, Riquet F, Duprez L, Vanden Berghe T, Takahashi N, Vandenabeele P. Necroptosis, in vivo detection in experimental disease models. Semin Cell Dev Biol. 2014;35: $2-13$.

74. Koo GB, Morgan MJ, Lee DG, Kim WJ, Yoon JH, Koo JS, et al. Methylation-dependent loss of RIP3 expression in cancer represses programmed necrosis in response to chemotherapeutics. Cell Res. 2015;25:707-25.

75. Moriwaki K, Bertin J, Gough PJ, Orlowski GM, Chan FK. Differential roles of RIPK1 and RIPK3 in TNF-induced necroptosis and chemotherapeutic agent-induced cell death. Cell Death Dis. 2015;6:e1636.

76. Bozec D, Iuga AC, Roda G, Dahan S, Yeretssian G. Critical function of the necroptosis adaptor RIPK3 in protecting from intestinal tumorigenesis. Oncotarget. 2016;7:46384-400.

77. Li L, Yu S, Zang C. Low necroptosis process predicts poor treatment outcome of human papillomavirus positive cervical cancers by decreasing tumor-associated macrophages M1 polarization. Gynecol Obstet Invest. 2018;83:259-67.

78. Hockendorf U, Yabal M, Herold T, Munkhbaatar E, Rott S, Jilg $\mathrm{S}$, et al. RIPK3 restricts myeloid leukemogenesis by promoting cell death and differentiation of leukemia initiating cells. Cancer Cell. 2016;30:75-91.

79. Kasof GM, Prosser JC, Liu D, Lorenzi MV, Gomes BC. The RIP-like kinase, RIP3, induces apoptosis and NF-kappaB nuclear translocation and localizes to mitochondria. FEBS Lett. 2000;473:285-91.

80. Mutirangura A, Pornthanakasem W, Sriuranpong V, Supiyaphun P, Voravud N. Loss of heterozygosity on chromosome 14 in nasopharyngeal carcinoma. Int J Cancer. 1998;78:153-6.

81. Papaemmanuil E, Hosking FJ, Vijayakrishnan J, Price A, Olver B, Sheridan E, et al. Loci on 7p12.2, 10q21.2 and 14q11.2 are associated with risk of childhood acute lymphoblastic leukemia. Nat Genet. 2009;41:1006-10.

82. Newton K, Sun X, Dixit VM. Kinase RIP3 is dispensable for normal NF-kappa Bs, signaling by the B-cell and T-cell receptors, tumor necrosis factor receptor 1, and Toll-like receptors 2 and 4. Mol Cell Biol. 2004;24:1464-9.

83. Wu J, Huang Z, Ren J, Zhang Z, He P, Li Y, et al. Mlkl knockout mice demonstrate the indispensable role of Mlkl in necroptosis. Cell Res. 2013;23:994-1006.

84. Gerl R, Vaux DL. Apoptosis in the development and treatment of cancer. Carcinogenesis. 2005;26:263-70.

85. Seifert L, Werba G, Tiwari S, Giao Ly NN, Alothman S, Alqunaibit $\mathrm{D}$, et al. The necrosome promotes pancreatic oncogenesis via CXCL1 and Mincle-induced immune suppression. Nature. 2016;532:245-9.

86. Seifert L, Miller G. Molecular pathways: the necrosome-A target for cancer therapy. Clin Cancer Res. 2017;23:1132-6.

87. Hanggi K, Vasilikos L, Valls AF, Yerbes R, Knop J, Spilgies $\mathrm{LM}$, et al. RIPK1/RIPK3 promotes vascular permeability to allow tumor cell extravasation independent of its necroptotic function. Cell Death Dis. 2017;8:e2588.

88. Ahn J, Xia T, Konno H, Konno K, Ruiz P, Barber GN. Inflammation-driven carcinogenesis is mediated through STING. Nat Commun. 2014;5:5166.

89. Lemos H, Mohamed E, Huang L, Ou R, Pacholczyk G, Arbab AS, et al. STING promotes the growth of tumors characterized by low antigenicity via IDO activation. Cancer Res. 2016;76:2076-81.

90. Huang C, Luo Y, Zhao J, Yang F, Zhao H, Fan W, et al. Shikonin kills glioma cells through necroptosis mediated by RIP-1. PLoS ONE. 2013;8:e66326.

91. Eil R, Vodnala SK, Clever D, Klebanoff CA, Sukumar M, Pan $\mathrm{JH}$, et al. Ionic immune suppression within the tumour microenvironment limits $\mathrm{T}$ cell effector function. Nature. 2016;537:539-43.

92. Grivennikov SI, Greten FR, Karin M. Immunity, inflammation, and cancer. Cell. 2010;140:883-99.

93. Krysko O, Aaes TL, Kagan VE, D'Herde K, Bachert C, Leybaert L, et al. Necroptotic cell death in anti-cancer therapy. Immunol Rev. 2017;280:207-19. 
94. Wang $\mathrm{T}$, Jin $\mathrm{Y}$, Yang $\mathrm{W}$, Zhang $\mathrm{L}$, Jin $\mathrm{X}$, Liu $\mathrm{X}$, et al. Necroptosis in cancer: an angel or a demon? Tumour Biol. 2017;39:1010428317711539.

95. Lalaoui N, Brumatti G. Relevance of necroptosis in cancer. Immunol Cell Biol. 2017;95:137-45.

96. Chen D, Yu J, Zhang L. Necroptosis: an alternative cell death program defending against cancer. Biochim Biophys Acta. 2016;1865:228-36.

97. Fulda S. Therapeutic exploitation of necroptosis for cancer therapy. Semin Cell Dev Biol. 2014;35:51-6.

98. Souers AJ, Leverson JD, Boghaert ER, Ackler SL, Catron ND, Chen J, et al. ABT-199, a potent and selective BCL-2 inhibitor, achieves antitumor activity while sparing platelets. Nat Med. 2013;19:202-8

99. Oltersdorf T, Elmore SW, Shoemaker AR, Armstrong RC, Augeri DJ, Belli BA, et al. An inhibitor of Bcl-2 family proteins induces regression of solid tumours. Nature. 2005;435:677-81.

100. Kotschy A, Szlavik Z, Murray J, Davidson J, Maragno AL, Le Toumelin-Braizat G, et al. The MCL1 inhibitor S63845 is tolerable and effective in diverse cancer models. Nature. 2016;538:477-82.

101. Ludwig LM, Nassin ML, Hadji A, LaBelle JL. Killing two cells with one stone: pharmacologic BCL-2 family targeting for cancer cell death and immune modulation. Front Pediatr. 2016; 4:135.

102. Derakhshan A, Chen Z, Van Waes C. Therapeutic small molecules target inhibitor of apoptosis proteins in cancers with deregulation of extrinsic and intrinsic cell death pathways. Clin Cancer Res. 2017;23:1379-87.

103. Casares N, Pequignot MO, Tesniere A, Ghiringhelli F, Roux S, Chaput $\mathrm{N}$, et al. Caspase-dependent immunogenicity of doxorubicin-induced tumor cell death. J Exp Med. 2005;202: 1691-701.

104. Spisek R, Charalambous A, Mazumder A, Vesole DH, Jagannath S, Dhodapkar MV. Bortezomib enhances dendritic cell (DC)mediated induction of immunity to human myeloma via exposure of cell surface heat shock protein 90 on dying tumor cells: therapeutic implications. Blood. 2007;109:4839-45.

105. Tesniere A, Schlemmer F, Boige V, Kepp O, Martins I, Ghiringhelli $\mathrm{F}$, et al. Immunogenic death of colon cancer cells treated with oxaliplatin. Oncogene. 2010;29:482-91.

106. Obeid M, Panaretakis T, Joza N, Tufi R, Tesniere A, van Endert $\mathrm{P}$, et al. Calreticulin exposure is required for the immunogenicity of gamma-irradiation and UVC light-induced apoptosis. Cell Death Differ. 2007;14:1848-50.

107. Garg AD, Krysko DV, Vandenabeele P, Agostinis P. Hypericinbased photodynamic therapy induces surface exposure of damage-associated molecular patterns like HSP70 and calreticulin. Cancer Immunol Immunother. 2012;61:215-21.

108. Vandenabeele P, Vandecasteele K, Bachert C, Krysko O, Krysko DV. Immunogenic apoptotic cell death and anticancer immunity. Adv Exp Med Biol. 2016;930:133-49.

109. Twyman-Saint Victor C, Rech AJ, Maity A, Rengan R, Pauken KE, Stelekati E, et al. Radiation and dual checkpoint blockade activate non-redundant immune mechanisms in cancer. Nature. 2015;520:373-7.

110. Jain MV, Paczulla AM, Klonisch T, Dimgba FN, Rao SB, Roberg K, et al. Interconnections between apoptotic, autophagic and necrotic pathways: implications for cancer therapy development. J Cell Mol Med. 2013;17:12-29.

111. Rongvaux A, Jackson R, Harman CC, Li T, West AP, de Zoete MR, et al. Apoptotic caspases prevent the induction of type I interferons by mitochondrial DNA. Cell. 2014;159: 1563-77.

112. White MJ, McArthur K, Metcalf D, Lane RM, Cambier JC, Herold MJ, et al. Apoptotic caspases suppress mtDNA-induced
STING-mediated type I IFN production. Cell. 2014;159:1549-62.

113. Giampazolias E, Zunino B, Dhayade S, Bock F, Cloix C, Cao K, et al. Mitochondrial permeabilization engages NF-kappaBdependent anti-tumour activity under caspase deficiency. Nat Cell Biol. 2017;19:1116-29.

114. Lee H, Shin EA, Lee JH, Ahn D, Kim CG, Kim JH, et al. Caspase inhibitors: a review of recently patented compounds (2013-2015). Expert Opin Ther Pat. 2018;28:47-59.

115. Ni HM, McGill MR, Chao X, Woolbright BL, Jaeschke H, Ding WX. Caspase inhibition prevents tumor necrosis factor-alphainduced apoptosis and promotes necrotic cell death in mouse hepatocytes in vivo and in vitro. Am J Pathol. 2016;186: 2623-36.

116. MacKenzie SH, Schipper JL, Clark AC. The potential for caspases in drug discovery. Curr Opin Drug Discov Devel. 2010;13:568-76.

117. Cho YS, Park HL. Exploitation of necroptosis for treatment of caspase-compromised cancers. Oncol Lett. 2017;14:1207-14.

118. Cho E, Lee JK, Park E, Seo CH, Luchian T, Park Y. Antitumor activity of HPA3P through RIPK3-dependent regulated necrotic cell death in colon cancer. Oncotarget. 2018;9:7902-17.

119. Fu Z, Deng B, Liao Y, Shan L, Yin F, Wang Z, et al. The antitumor effect of shikonin on osteosarcoma by inducing RIP1 and RIP3 dependent necroptosis. BMC Cancer. 2013;13:580.

120. Xuan Y, Hu X. Naturally-occurring shikonin analogues-a class of necroptotic inducers that circumvent cancer drug resistance. Cancer Lett. 2009;274:233-42.

121. Han W, Li L, Qiu S, Lu Q, Pan Q, Gu Y, et al. Shikonin circumvents cancer drug resistance by induction of a necroptotic death. Mol Cancer Ther. 2007;6:1641-9.

122. Cekay MJ, Roesler S, Frank T, Knuth AK, Eckhardt I, Fulda S. Smac mimetics and type II interferon synergistically induce necroptosis in various cancer cell lines. Cancer Lett. 2017;410:228-37.

123. McCabe KE, Bacos K, Lu D, Delaney JR, Axelrod J, Potter MD, et al. Triggering necroptosis in cisplatin and IAP antagonist-resistant ovarian carcinoma. Cell Death Dis. 2014;5: e1496.

124. Steinhart L, Belz K, Fulda S. Smac mimetic and demethylating agents synergistically trigger cell death in acute myeloid leukemia cells and overcome apoptosis resistance by inducing necroptosis. Cell Death Dis. 2013;4:e802.

125. Jing L, Song F, Liu Z, Li J, Wu B, Fu Z, et al. MLKL-PITPalpha signaling-mediated necroptosis contributes to cisplatin-triggered cell death in lung cancer A549 cells. Cancer Lett. 2018;414: $136-46$

126. Xu Y, Lin Z, Zhao N, Zhou L, Liu F, Cichacz Z, et al. Receptor interactive protein kinase 3 promotes Cisplatin-triggered necrosis in apoptosis-resistant esophageal squamous cell carcinoma cells. PLoS ONE. 2014;9:e100127.

127. Yang H, Ma Y, Chen G, Zhou H, Yamazaki T, Klein C, et al. Contribution of RIP3 and MLKL to immunogenic cell death signaling in cancer chemotherapy. Oncoimmunology. 2016;5: e1149673.

128. Chesi M, Mirza NN, Garbitt VM, Sharik ME, Dueck AC, Asmann YW, et al. IAP antagonists induce anti-tumor immunity in multiple myeloma. Nat Med. 2016;22:1411-20.

129. He GW, Gunther C, Thonn V, Yu YQ, Martini E, Buchen B, et al. Regression of apoptosis-resistant colorectal tumors by induction of necroptosis in mice. J Exp Med. 2017;214:1655-62.

130. Rodriguez-Madoz JR, Zabala M, Alfaro M, Prieto J, Kramer MG, Smerdou C. Short-term intratumoral interleukin-12 expressed from an alphaviral vector is sufficient to induce an efficient antitumoral response against spontaneous hepatocellular carcinomas. Hum Gene Ther. 2014;25:132-43. 
131. Murugesan SR, King CR, Osborn R, Fairweather WR, O'Reilly EM, Thornton MO, et al. Combination of human tumor necrosis factor-alpha (hTNF-alpha) gene delivery with gemcitabine is effective in models of pancreatic cancer. Cancer Gene Ther. 2009;16:841-7.

132. Zitvogel L, Tahara H, Cai Q, Storkus WJ, Muller G, Wolf SF, et al. Construction and characterization of retroviral vectors expressing biologically active human interleukin-12. Hum Gene Ther. 1994;5:1493-506.

133. Riediger C, Wingender G, Knolle P, Aulmann S, Stremmel W, Encke J. Fms-like tyrosine kinase 3 receptor ligand (Flt3L)-based vaccination administered with an adenoviral vector prevents tumor growth of colorectal cancer in a BALB/c mouse model. J Cancer Res Clin Oncol. 2013;139:2097-110.

134. Tandon M, Vemula SV, Sharma A, Ahi YS, Mittal S, Bangari DS, et al. EphrinA1-EphA2 interaction-mediated apoptosis and FMS-like tyrosine kinase 3 receptor ligand-induced immunotherapy inhibit tumor growth in a breast cancer mouse model. J Gene Med. 2012;14:77-89.

135. Hou S, Kou G, Fan X, Wang H, Qian W, Zhang D, et al. Eradication of hepatoma and colon cancer in mice with Flt3L gene therapy in combination with 5-FU. Cancer Immunol Immunother. 2007;56:1605-13.

136. Liu A, Guardino A, Chinsangaram L, Goldstein MJ, Panicali D, Levy R. Therapeutic vaccination against murine lymphoma by intratumoral injection of recombinant fowlpox virus encoding CD40 ligand. Cancer Res. 2007;67:7037-44.

137. Kikuchi T, Crystal RG. Anti-tumor immunity induced by in vivo adenovirus vector-mediated expression of CD40 ligand in tumor cells. Hum Gene Ther. 1999;10:1375-87.

138. del Campo AB, Aptsiauri N, Mendez R, Zinchenko S, Vales A, Paschen A, et al. Efficient recovery of HLA class I expression in human tumor cells after beta2-microglobulin gene transfer using adenoviral vector: implications for cancer immunotherapy. Scand J Immunol. 2009;70:125-35.

139. Hung KS, Hong CY, Lee J, Lin SK, Huang SC, Wang TM, et al. Expression ofp16(INK4A) induces dominant suppression of glioblastoma growth in situ through necrosis and cell cycle arrest. Biochem Biophys Res Commun. 2000;269:718-25.

140. Caruso M, Panis Y, Gagandeep S, Houssin D, Salzmann JL, Klatzmann D. Regression of established macroscopic liver metastases after in situ transduction of a suicide gene. Proc Natl Acad Sci USA. 1993;90:7024-8.

141. Culver KW, Ram Z, Wallbridge S, Ishii H, Oldfield EH, Blaese RM. In vivo gene transfer with retroviral vector-producer cells for treatment of experimental brain tumors. Science. 1992;256:1550-2.

142. Xie X, Zhao X, Liu Y, Zhang J, Matusik RJ, Slawin KM, et al. Adenovirus-mediated tissue-targeted expression of a caspase-9based artificial death switch for the treatment of prostate cancer. Cancer Res. 2001;61:6795-804.

143. Shariat SF, Desai S, Song W, Khan T, Zhao J, Nguyen C, et al. Adenovirus-mediated transfer of inducible caspases: a novel "death switch" gene therapeutic approach to prostate cancer. Cancer Res. 2001;61:2562-71.
144. Zappasodi R, Merghoub T, Wolchok JD. Emerging concepts for immune checkpoint blockade-based combination therapies. Cancer Cell. 2018:33:581-98.

145. Gandhi L, Rodriguez-Abreu D, Gadgeel S, Esteban E, Felip E, De Angelis F, et al. Pembrolizumab plus chemotherapy in metastatic non-small-cell lung cancer. N Engl J Med. 2018;378:2078-92.

146. Abdo J, Cornell DL, Mittal SK, Agrawal DK. Immunotherapy plus cryotherapy: potential augmented abscopal effect for advanced cancers. Front Oncol. 2018;8:85.

147. Binnewies M, Roberts EW, Kersten K, Chan V, Fearon DF, Merad $\mathrm{M}$, et al. Understanding the tumor immune microenvironment (TIME) for effective therapy. Nat Med. 2018;24:541-50.

148. Gajewski TF. The next hurdle in cancer immunotherapy: overcoming the non-T-cell-inflamed tumor microenvironment. Semin Oncol. 2015;42:663-71.

149. Anderson KG, Stromnes IM, Greenberg PD. Obstacles posed by the tumor microenvironment to $\mathrm{T}$ cell activity: a case for synergistic Therapies. Cancer Cell. 2017;31:311-25.

150. Lanitis E, Dangaj D, Irving M, Coukos G. Mechanisms regulating T-cell infiltration and activity in solid tumors. Ann Oncol. 2017;28(Suppl_12):xii18-xii32.

151. Spranger S, Gajewski TF. Tumor-intrinsic oncogene pathways mediating immune avoidance. Oncoimmunology. 2016;5: e1086862.

152. Gajewski TF, Schreiber H, Fu YX. Innate and adaptive immune cells in the tumor microenvironment. Nat Immunol. 2013;14: 1014-22.

153. Teng MW, Ngiow SF, Ribas A, Smyth MJ. Classifying cancers based on T-cell infiltration and PD-L1. Cancer Res. 2015;75:2139-45.

154. Ribas A, Tumeh PC. The future of cancer therapy: selecting patients likely to respond to PD1/L1 blockade. Clin Cancer Res. 2014;20:4982-4.

155. Cogdill AP, Andrews MC, Wargo JA. Hallmarks of response to immune checkpoint blockade. Br J Cancer. 2017;117:1-7.

156. Harlin H, Meng Y, Peterson AC, Zha Y, Tretiakova M, Slingluff $\mathrm{C}$, et al. Chemokine expression in melanoma metastases associated with CD8+T-cell recruitment. Cancer Res. 2009;69: 3077-85.

157. Dagogo-Jack I, Shaw AT. Tumour heterogeneity and resistance to cancer therapies. Nat Rev Clin Oncol. 2018;15:81-94.

158. June $\mathrm{CH}$, Warshauer JT, Bluestone JA. Is autoimmunity the Achilles' heel of cancer immunotherapy? Nat Med. 2017;23: 540-7.

159. Yang $\mathrm{L}, \mathrm{Yu} \mathrm{H}$, Dong $\mathrm{S}$, Zhong $\mathrm{Y}, \mathrm{Hu} \mathrm{S}$. Recognizing and managing on toxicities in cancer immunotherapy. Tumour Biol. 2017;39:1010428317694542.

160. Puzanov I, Diab A, Abdallah K, Bingham CO 3rd, Brogdon C, Dadu R, et al. Managing toxicities associated with immune checkpoint inhibitors: consensus recommendations from the Society for Immunotherapy of Cancer (SITC) Toxicity Management Working Group. J Immunother Cancer. 2017;5:95.

161. Sharma P, Hu-Lieskovan S, Wargo JA, Ribas A. Primary, adaptive, and acquired resistance to cancer immunotherapy. Cell. 2017;168:707-23. 